\title{
Evidence to practice: treatment of anxiety in individuals with autism spectrum disorders
}

\author{
This article was published in the following Dove Press journal: \\ Neuropsychiatric Disease and Treatment \\ 24 January 2011 \\ Number of times this article has been viewed
}

Russell Lang

Richard Mahoney

Farah El Zein

Elizabeth Delaune

Megan Amidon

Texas State University-San Marcos, TX, USA

Date of preparation: 23rd December 2010

Conflict of interest: None declared
Clinical question: What treatment improves social interactions and reduces reports of anxiety symptoms in individuals with autism spectrum disorders (ASD) and a co-occurring anxiety disorder?

Results: Systematic reviews and randomized clinical trials suggest that cognitive behavior therapy in tandem with direct instruction of social skills using applied behavior analysis intervention components may be effective for treating anxiety in individuals with high functioning ASD. For individuals with ASD, an anxiety disorder, and an intellectual disability, systematic desensitization may be effective.

Implementation: Intervention should emphasize teaching social skills. Reinforcers (ie, rewards based upon the client's interests) should be used to encourage participation in therapy. Treatment should incorporate visual aides and family involvement. Intervention components involving abstract concepts, visualization, and discussions of emotions are less useful given difficulties in abstract reasoning and communication inherent to ASD.

Keywords: autism, ASD, Asperger's, anxiety, cognitive behavior therapy, applied behavior analysis

\section{Anxiety in autism}

Definition: The diagnostic characteristics of ASD include impaired social skills, delayed development of language, and repetitive or restrictive interests or body movements. Anxiety disorders are characterized by a disproportionate fear reaction to relatively benign environmental stimuli. Individuals with co-occurring ASD and an anxiety disorder present with particularly complex behaviors that require a unique approach to treatment.

Etiology: The cause of ASD is not known. However, it is likely multifactorial with many agents, genetic and environmental, possibly affecting the presentation of symptoms. ${ }^{1}$ A common hypothesis for the cause of anxiety in children with ASD involves an ASD symptom leading to failure to function normally within common situations. For example, a child with social skills deficits may come to experience anxiety in social situations as a result of previous social failures. Similarly, a child with unusual aversions to common sensory stimuli (eg, ordinary noises) may experience anxiety in situations in which the occurrence of specific audible, visual, or tactile stimuli is possible or probable..$^{2-4}$

Incidence: The prevalence of ASD is 1 in 150 children. ${ }^{5}$ Estimates of the prevalence of anxiety disorders in the ASD population vary from $11 \%$ to $84 \%{ }^{2}$ 
Economics: The estimated cost for a comprehensive treatment of 1 child with ASD for 1 year ranges from US\$20,000 to US $\$ 60,000$ dollars. ${ }^{6}$ Because anxiety may exacerbate ASD symptoms and complicate treatment, the cost of treating a child with ASD and an anxiety disorder is likely to be in the higher end of the range.

Level of evidence used in this summary: Systematic reviews and randomized clinical trials (RCTs).

Search procedures: The electronic databases PsychInfo, Medline, PubMed, Cochrane Library, and Educational Resources Information Center (ERIC) were searched using the terms "autism" or "Aspergers" paired with "anxiety" and either "treatment", "intervention", or "therapy".

Outcomes: From the patient and family perspective the most meaningful outcomes are:
1. Improved social interactions

2. Reduced reports of stress and anxiety

Consumer summary: ASD is characterized by problems with social interaction, communication, and limited interests or repetitive behaviors. Anxiety disorders often involve similar symptoms resulting in excessive worry about everyday life events when no obvious reasons for worry are present. Anxiety is common in individuals with ASD and may complicate treatments designed to improve the symptoms of ASD. The best available evidence suggests that using a combination of procedures designed to teach social skills, reward treatment compliance, and individualize intervention sessions by incorporating the preferred interests and activities of the client is effective.

\section{The evidence}

Systematic reviews: $\quad 4$

Meta-analysis: $\quad 0$

Randomized clinical trials (RCTs): $\quad 2$

The systematic reviews included case studies, single subject designs, group designs that were not RCTs, and RCTs. $^{2,7-9}$ One review divided 14 treatment studies in to three categories (ie, psychopharmacological, psychosocial, and alternative) and reported that psychosocial (ie, cognitive behavior therapy, CBT) had the best available evidence. ${ }^{2}$ Another review examined only behavioral interventions (ie, based upon behavior modification and/ or applied behavior analysis, ABA) for anxiety in children with intellectual disabilities and ASD, and recommended graduated exposure (systematic desensitization) and reinforcement. ${ }^{7}$ The two most recent reviews focused solely on CBT and determined that CBT modified by including $\mathrm{ABA}$ intervention components designed to teach social skills using visual aides, family involvement, individualized reinforcers, and systematic desensitization are effective in treating anxiety in individuals with ASDs described as "high functioning" (eg, Asperger's syndrome). ${ }^{8,9}$
The RCTs (see Table 1) found CBT modified by a) increasing family involvement, b) increasing emphasis on direct instruction of social skills, c) embedding perseverative interests within the treatment sessions, d) providing individualized reinforcers for treatment compliance, and e) reducing emphasis on abstract concepts, emotions, and f) visualization to improve anxiety symptoms. However, improvements were observed only in individuals without intellectual disability (ie, high functioning ASD) were effective.

\section{Conclusions}

For individuals with an ASD and an anxiety disorder but no intellectual disability, CBT is supported by research when it is modified by direct instruction of social skills, increased family involvement, visual supports, individualized reinforcers, embedded perseverative interests in sessions, and reduced emphasis on abstract concepts and visualization. For individuals with an ASD and an anxiety disorder who do have an intellectual disability, much less evidence is available. However, one systematic review suggests that behavioral approaches including contingent reinforcement and graduated exposure may be effective. ${ }^{7}$ 
Table I RCTs examining treatments for anxiety in people with ASD

\begin{tabular}{|c|c|c|c|}
\hline Authors & Number randomized and characteristics & Intervention & Results \\
\hline Sofronoff et al ${ }^{10}$ & $\begin{array}{l}\text { 7I children with Asperger's syndrome } \\
\text { and panic disorder, obsessive compulsive } \\
\text { disorder, social phobia, separation anxiety } \\
\text { disorder, or generalized anxiety disorder }\end{array}$ & $\begin{array}{l}6 \text { sessions } 2 \text { hours } \\
\text { each of modified CBT }\end{array}$ & $\begin{array}{l}\text { Significant reduction in parent-rated } \\
\text { symptoms at 6-week follow-up, } \\
\text { significant increase in the number } \\
\text { of strategies participants were able } \\
\text { to describe to cope with anxiety } \\
\text { producing situations }\end{array}$ \\
\hline Wood et al"I & $\begin{array}{l}40 \text { children ( } 4 \text { drop outs) with ASDs } \\
\text { and social phobia, separation anxiety disorder, } \\
\text { obsessive compulsive disorder, or generalized } \\
\text { anxiety disorder }\end{array}$ & $\begin{array}{l}16 \text { sessions I. } 5 \text { hours } \\
\text { each of modified CBT }\end{array}$ & $\begin{array}{l}\text { Significant reduction in parent reported } \\
\text { anxiety scores, no significant change } \\
\text { in child reported anxiety, } 93 \% \text { met criteria } \\
\text { for positive response to treatment, } \\
64 \% \text { of treatment group no longer met } \\
\text { criteria for any anxiety disorder compared } \\
\text { to } 9 \% \text { of control group }\end{array}$ \\
\hline
\end{tabular}

Abbreviations: ASD, autism spectrum disorders; CBT, cognitive behavior therapy; RCT, randomized clinical trials.

\section{Further reading for evidence}

- Chalfant AM, Rapee R, Carroll L. Treating anxiety disorders in children with high functioning autism spectrum disorders: A controlled trial. $J$ Autism Dev Disord. 2007;37:1842-1857.
- Reaven JA, Blakeley-Smith A, Nichols S, Dasari M, Flanigan E, Hepburn S. Cognitive-behavioral group treatment for anxiety symptoms in children with high functioning autism spectrum disorders: a pilot study. Focus Autism Other Dev Disabil. 2009;24:27-37.

\section{The practice}

\section{Potential pitfalls}

- Individuals with ASD who have social impairments may be the target of harassment and bullying; therefore, anxiety symptoms may be due to an actual increased risk of harm and not cognitive dysfunction.

- Individuals with intellectual disabilities and/or severe communication deficits may not be capable of forming the traditional therapeutic relationship sought during CBT and may struggle to recognize and share thoughts, feelings, and abstract concepts.

- Modifying CBT to be effective with children with ASD may require the support of an expert trained to conduct behavioral assessments (eg, functional behavioral assessment and preference assessments) and provide direct instruction of social skills using reinforcement procedures.

\section{Management}

The length of treatment reported across RCTs and systematic reviews varied from six to 16 sessions of one to two hours per session. Each intervention was conducted within a time frame of six weeks to six months and was implemented by highly trained therapists with expertise in ASD.

\section{Assessment}

Anxiety can be conceptualized from a behavior analytic perspective as escape maintained behavior. Specifically, overt behaviors (behaviors that can be easily observed such as elopement and tantrums) and covert behaviors (internal states more difficult to observe such as increased heart rate) associated with anxiety are reinforced by escape from anxiety producing situations or stimuli. For example, contingent upon the occurrence of anxiety symptoms, caregivers may recognize that the individual is in distress and take steps to remove him or her from the perceived cause of anxiety (eg, leaving the social situation or removing difficult or aversive task demands). For people with ASD, anxiety might serve as a means of communicating a desire to escape from a situation. ${ }^{12}$ Effective treatment decisions can be made if the function of the behaviors associated with anxiety can be determined. A functional behavioral assessment or functional analysis is 
an assessment protocol that can be used to identify possible communicative functions for anxiety symptoms in people with ASD. A reference that provides a description of functional assessment procedures is provided below.

\section{Treatment}

CBT typically includes some form and sequence of the following treatment components. a) The patient is told the origin of their anxiety symptoms in order to help them realize that feeling anxious is not their fault. b) The therapist works with the client to help them realize the impact of anxiety and the need for change. c) A ranking of situations or stimuli from least to most anxiety producing is created. d) Clients are gradually exposed to the least producing anxiety situations/ stimuli first while simultaneously learning to control their fear. e) The client is taught a variety of coping behaviors (eg, relaxation techniques) to help them manage their anxiety.

When used with individuals with ASD who do not have an intellectual disability, the above CBT procedures are modified by reducing the emphasis on abstract discussions of thoughts and feelings and by increasing the emphasis on the graduated exposure and teaching social skills as a coping mechanism. Additionally, rewards are given to improve compliance during treatment, visual aids are used as instructional tools, and the clients' families are encouraged to participate. For individuals who also have an intellectual disability, graduated exposure and/or functional assessment followed by a function-based intervention is recommended (see Friman 2007 for additional function-based procedures).

\section{Further reading for practice}

- Friman P. The fear factor: A functional perspective on anxiety. In: Functional Analysis in Clinical Treatment. Sturmey P, ed. San Diego, CA, US: Elsevier Academic Press, 2007:335-355.
- Attwood T. Cognitive behavior therapy for children and adults with Asperger's syndrome. Behav Change. 2004; 21147-21161.

- Reaven JA. Children with high-functioning autism spectrum disorders and co-occurring anxiety symptoms: Implications for assessment and treatment. J Spec Pediatr Nurs. 2009;14:192-199.

\section{References}

1. O'Roak BJ, State MW. Autism genetics: Strategies, challenges, and opportunities. Autism Res. 2008;1:4-17.

2. White SW, Oswal D, Ollendick T, Scahill L. Anxiety in children and adolescents with autism spectrum disorders. Clin Psychol Rev. 2009; 29:216-229.

3. Bellini S. The development of social anxiety in adolescents with autism spectrum disorders. Focus Autism Other Dev Disabil. 2006; 21:138-145.

4. White SW, Roberson-Nay R. Anxiety, social deficits, and loneliness in youth with autism spectrum disorders. J Autism Dev Disord. 2009; 39:1006-1013.

5. Coo H, Oullette-Kuntz H, Lloyd JE, Kasmara L, Holden JJ, Lewis S. Trends in autism prevalence: Diagnostic substitution revisited. JAutism Dev Disord. 2008:1036-1046.

6. Chasson GS, Harris GE, Neely WJ. Cost comparison of early intensive behavioral intervention and special education for children with autism. J Child Fam Stud. 2007;16:401-416.

7. Hagopian LP, Jennett HK. Behavioral assessment and treatment of anxiety in individuals with intellectual disabilities and autism. $J$ Dev Phys Disabil. 2008;20:467-483.

8. Lang R, Regester A, Lauderdale S, Ashbaugh K, Harring A. Treatment of anxiety in autism spectrum disorders using cognitive behavior therapy: A systematic review. Dev Neurorehab. 2010;13:53-63.

9. Moree BN, Davis TE. Cognitive-behavioral therapy for anxiety in children diagnosed with autism spectrum disorders: Modification trends. Res Autism Spectrum Disord. 2010;4:346-354.

10. Sofronoff K, Attwood T, Hinton S. A randomized controlled trial of a CBT intervention for anxiety in children with Asperger syndrome. J Child Psychol Psychiatr. 2005;46:1152-1160.

11. Wood JJ, Drahota A, Sze K, Har K, Chiu A, Langer DA. Cognitive behavioral therapy for anxiety in children with autism spectrum disorders: a randomized, controlled trial. J Child Psychol Psychiatr. 2009;50:224-234.

12. Friman P, Hayes SC, Wilson KG. Why behavior analysts should study emotion: the example of anxiety. J Appl Behav Anal. 1998;31: 137-156.
Neuropsychiatric Disease and Treatment

\section{Publish your work in this journal}

Neuropsychiatric Disease and Treatment is an international, peerreviewed journal of clinical therapeutics and pharmacology focusing on concise rapid reporting of clinical or pre-clinical studies on a range of neuropsychiatric and neurological disorders. This journal is indexed on PubMed Central, the 'PsycINFO' database and CAS, and is the official

\section{Dovepress}

journal of The International Neuropsychiatric Association (INA). The manuscript management system is completely online and includes a very quick and fair peer-review system, which is all easy to use. Visit $\mathrm{http}: / / \mathrm{www}$.dovepress.com/testimonials.php to read real quotes from published authors. 